\title{
Admission of demented old people to psychiatric units: an assessment of recent trends
}

The trend in the numbers and rates of elderly demented patients being admitted to psychiatric units in England was shown to have reversed from 1970 , the decline continuing until 1974 despite a substantial increase in the very elderly population. ${ }^{1}$ We report data for $1975-83$ which show that this trend has again changed and offer some possible explanations.

\section{Present data}

From 1973 to 1983 "all admissions" for dementia doubled in England. "First admissions" increased, but at a slower pace, and in 1981 (the last year for which data were available) had only just regained the 1970 level (figure). of provision for the elderly in the community, ${ }^{34}$ there is growing pressure on already thinly stretched National Health Service resources, so that a "revolving door" policy is used of necessity rather than by choice. The increased need for readmission would thus reflect a burden carried by the carers which is not adequately relieved by resources outside the hospital.

Probably each of these factors may be playing a part. The full effects of the recent massive increase in the private sector ${ }^{5}$ have yet to be seen in published hospital admission data and future trends will be of interest. The selective nature of private care, along with the recent "capping" of Department of Health and Social Security rates for private care, may lead to an increased concentration in hospitals of behaviourally disturbed and deeply dependent

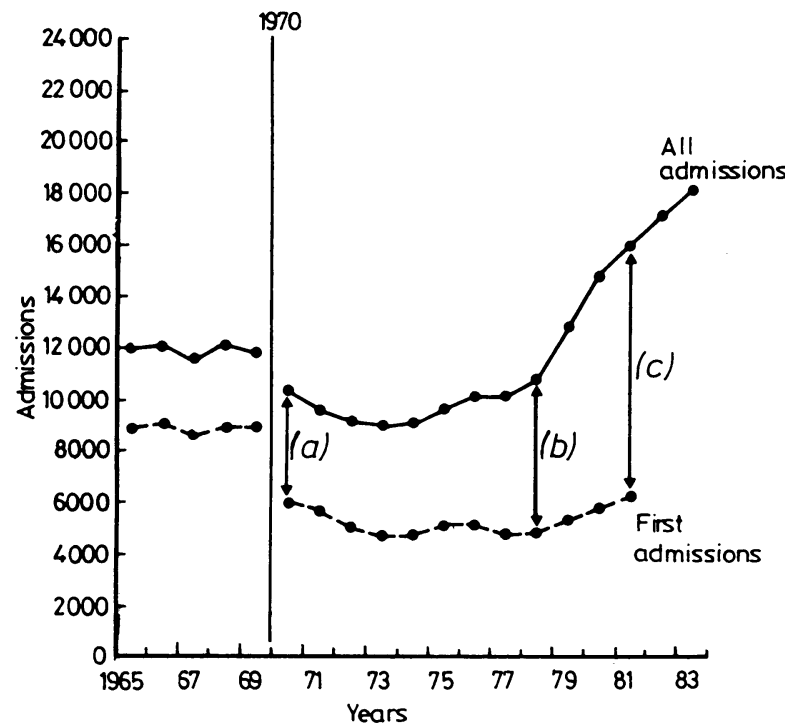

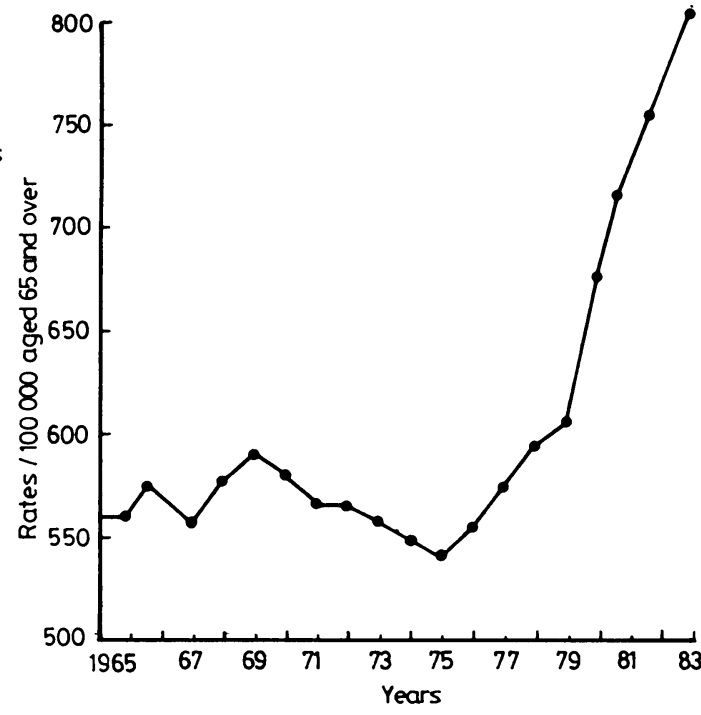

LEFT: All and first admissions for senile and presenile dementia in England during 1965-83 (ratio of all admissions to first admissions: (a) $1 \cdot 67,(b) 2 \cdot 18,(c) 2 \cdot 62$ ). RIGHT: All admissions of patients aged 65 and over to mental illness hospitals in England and Wales during 1965 83.

That the increased numbers of old people would have led to more admissions is unlikely to be the sole explanation: the admission rate for over $65 \mathrm{~s}$ for all diagnoses also showed a $45 \%$ increase during $1973-83$ (see figure), whereas the increase in the rate of first admissions for the same period was only marginal.

\section{Comment}

The fall in admissions from 1970 to 1974 has been attributed to the reluctance of psychiatrists to admit old people, especially those who are demented, in the wake of publicity following the Ely Hospital report and subsequent "scandals" and the establishment of the Hospital (later Health) Advisory Service. ${ }^{1}$ Since then there have been many new consultant posts with a special responsibility for psychogeriatrics, ${ }^{2}$ and special services have developed widely. This is likely to have led to a more active approach to dementia and a greater readiness to take responsibility for the demented. The increase in all admissions and the widening gap between all admissions and first admissions may therefore represent good use of hospital beds, with readmissions for relief care.

A more gloomy interpretation would be that as financial stringency leads to the abandonment of central norms and a relative reduction of some forms demented people who may be rejected by a selective private sector in favour of those who are less difficult and therefore less expensive to look after.

1 Shulman K, Arie T. Fall in admission rate of old people to psychiatric units. BrMed $\mathcal{f}$ 1978; ; 156-8. 2 Wattis J, Wattis L, Arie T. Psychogeriatrics: a national survey of a new branch of psychiatry. $B r$ Med f 1981;282:1529-33.

3 Department of Health and Social Security. Health care and its costs-the development of the National Health Service in England. London: HMSO, 1983.

4 Wenger C. Care in the community. Ageing and Society 1985;5:143-9.

5 Office of Health Economics. Private health care 1985. London: OHE, 1985

(Accepted 23 December 1985)

Department of Health Care of the Elderly, Queen's Medical Centre, Nottingham NG7 2UH

C W SMITH, BA, PHD, research officer

C J STALEY, BM, MRCPSYCH, senior registrar

T ARIE, FRCPSYCH, FRCP, professor

Correspondence to: Dr Smith. 